\title{
Case report. Een ongewone complicatie van suprapubische katheterisatie: accidentele plaatsing van de katheter in de ureter
}

\author{
Nicolas Vos · Eveline M. P. Broers ${ }^{1}$ Elisabeth M. Groenewegen² \\ Published online: 13 June 2019 \\ (c) The Author(s) 2019
}

\section{Samenvatting}

Suprapubische katheterisatie is een belangrijke techniek om de blaas te draineren en is geassocieerd met enkele bekende complicaties, zoals het ontwikkelen van een opstijgende urineweginfectie of perforatie van een darmlis tijdens plaatsing van de katheter. In deze casus beschrijven we een ongewone complicatie die kan optreden tijdens het wisselen van de suprapubische katheter (SPC), namelijk plaatsing van de katheter in een van de ureteren, met obstructie en hydronefrose tot gevolg. Het is een zeldzaam fenomeen, dat kan leiden tot een serieuze diagnostische uitdaging bij een specifieke patiëntenpopulatie.

Trefwoorden suprapubisch $\cdot$ katheter $\cdot$ ureter $\cdot$ obstructie $\cdot$ hydronefrose

\section{Case report. An unusual complication of suprapubic cystostomy: inadvertent placement of a catheter into the ureter}

\begin{abstract}
Suprapubic cystostomy is an important technique for drainage of the bladder and is associated with some well-known complications, such as a symptomatic urinary tract infection or perforation of the bowel during insertion of the catheter. In this case report, we describe an unusual complication that can occur during the change of the suprapubic catheter (SPC), namely placement of the catheter into one of the ureters, with obstruction and hydronephrosis as a severe consequence. Being a rare event, this phenomenon has serious diagnostic challenges in a certain group of patients.
\end{abstract}

Keywords suprapubic $\cdot$ catheter $\cdot$ ureter $\cdot$ obstruction $\cdot$ hydronephrosis

\section{Introductie}

Suprapubische katheterisatie is een effectieve en veel gebruikte techniek bij het management van urineretentie en -incontinentie. Het wordt beschouwd als een veilige en patiëntvriendelijke procedure, maar complicaties kunnen optreden. De ernst van deze complicaties varieert van mild, bijvoorbeeld het ontwikkelen van intermittente macroscopische hematurie, tot ernstig, zoals een darmperforatie tijdens de plaatsing van de katheter. In deze casus wordt het zeld-

Nicolas Vos

nicolas.vos@outlook.com

1 afdeling Urologie, Maxima Medisch Centrum, Veldhoven, Nederland

2 Universiteit Maastricht, Maastricht, Nederland zame en atypische beloop van plaatsing van de katheter in de rechter ureter beschreven, met ureterale obstructie en hydronefrose als gevolg.

\section{Casus}

Een 78-jarige Nederlandse vrouw, die reeds jaren een suprapubische katheter (SPC) had in verband met storende nachtelijke incontinentie, werd in oktober 2018 van een verpleeghuis naar de spoedeisende hulp (SEH) gebracht met algemene malaise, nausea, verminderde intake, koorts, en macroscopische hematurie. Deze was korte tijd na het wisselen van de SPC ontstaan. De patiënte had verder een significante medische voorgeschiedenis, met onder andere gecompliceerde diabetes mellitus type 2 en vasculaire dementie. 


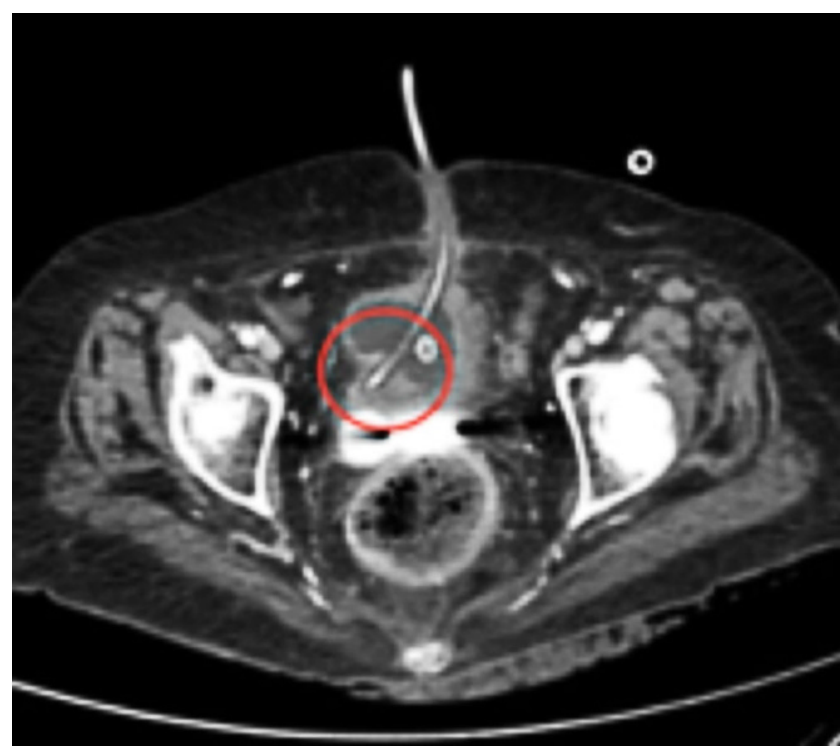

Figuur 1 Migratie van de SPC in het rechterostium. Ook de TUC is zichtbaar in de blaas

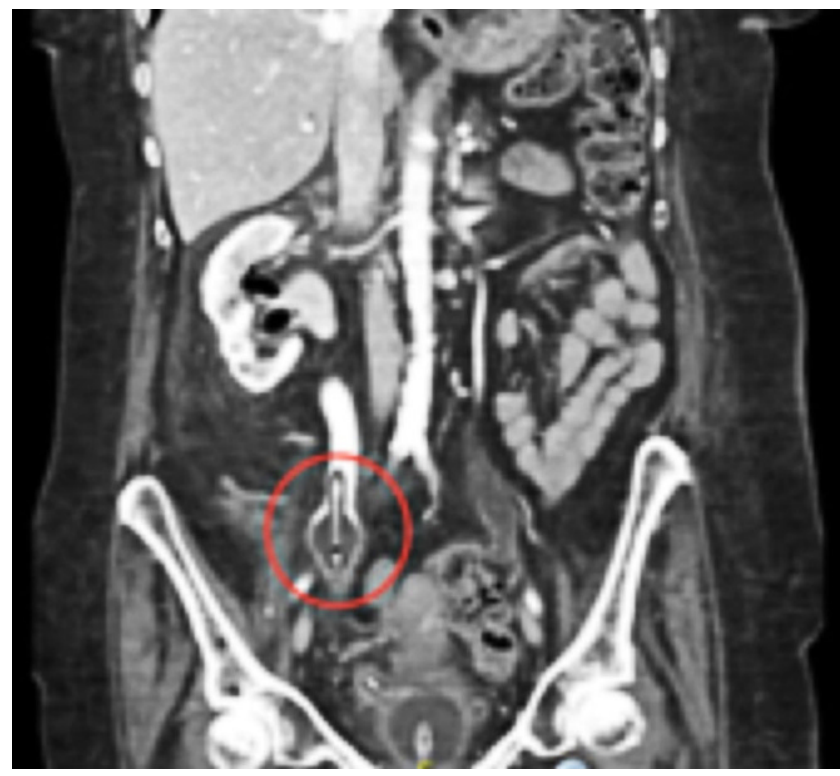

Figuur 2 Opgeblazen ballon halverwege de ureter met proximaal daarvan de via de SPC geïnjecteerde contrastvloeistof en met en een duidelijke dilatatie van het pyelocalicieel systeem

Lichamelijk onderzoek op de SEH toonde normale vitale parameters, behoudens de koorts, en een duidelijke rechter nierslagpijn. De infectieparameters in het bloed bleken verhoogd en de klaring bleek gedaald. Het urinesediment was verontreinigd. Een echografie toonde hydronefrose aan de rechterzijde, een normale positie van de net geplaatste transurethrale katheter (TUC), en een onduidelijke positie van de SPC. Er werd een CT-abdomen uitgevoerd, waarbij contrast via de SPC werd geïnjecteerd. Deze toonde de oorzaak van het ziektebeeld: de SPC bleek geplaatst te zijn in de rechterureter (fig. 1). De opgeblazen ballon bevond zich ongeveer halfweg het verloop van de ureter (fig. 2).

De ballon werd leeggehaald en de SPC teruggetrokken in de blaas. Er werd gestart met intraveneuze antibiotica (piperacilline/tazobactam) op basis van een eerder antibiogram. De bloedkweken bleken uiteindelijk negatief, en de huidige urinekweek toonde een infectie met Candica albicans, waarvoor werd geswitcht naar fluconazol per os gedurende vier weken. De hydronefrose rechts was bij een volgende echografie niet meer zichtbaar. De SPC werd nogmaals gewisseld door ervaren urologische verpleegkundigen, waarna de patiënte in goede algemene toestand het ziekenhuis kon verlaten.

\section{Discussie}

Suprapubische katheterisatie is een veelgebruikte techniek in de urologische praktijk. Het biedt een alternatieve manier voor drainage van urine wanneer een andere methode, namelijk transurethrale of intermittente (zelf)katheterisatie, niet haalbaar of ongewenst is. Bekende complicaties die zijn gerelateerd aan de plaatsing en/of aanwezigheid van de SPC zijn onder andere het optreden van een forse nabloeding, ontwikkeling van een katheter-geassocieerde urineweginfectie en vorming van blaasstenen $[1,2]$.

Het accidenteel plaatsen en opblazen van de ballon van een katheter in de ureter, met secundair het ontwikkelen van een ureterale obstructie, is een zeer zeldzame en potentieel ernstige complicatie. Voor zover ons bekend, zijn er slechts een tiental casussen beschreven. Bij de meerderheid van deze gevallen betreft het ook een transurethrale, en geen suprapubische katheter [3-6]. Daarnaast is het belangrijk om een onderscheid te maken tussen obstructie door plaatsing van een behoorlijke lengte van de katheter in de ureter enerzijds, en obstructie ontstaan door (herhaaldelijke) migratie van de tip van de katheter in een van de ostia anderzijds, een complicatie die wel vaker wordt genoemd [7-12].

Uit de beschikbare literatuur kan worden opgemaakt dat incorrecte plaatsing en/of migratie van de katheter in de ureter voornamelijk voorkomt bij patiënten die chronisch een katheter hebben, meestal in het kader van neurogeen blaaslijden. Deze patiënten hebben vaak een kleiner blaasvolume, vesico-ureterale reflux, en ostia die meer geopend zijn. Ook het plaatsen van een katheter in een lege blaas doet het risico op ureterale katheterisatie toenemen [3-6]. Daarnaast kunnen patiënten met een neurogene blaas een verminderd blaasgevoel hebben, waardoor de eerste symptomen van een verkeerde ligging van de katheter pas laat optreden. Klassieke symptomen zijn pijn (abdominaal, inguïnaal of dorsaal), urinelekkage langs de insteekopening, en verstopping van de katheter. Ook toename van pijn tij- 
dens het spoelen van de katheter is een typisch (en logisch) teken van een aberrante ligging $[3,6]$.

Zoals onze casus goed weergeeft, is een verkeerd geplaatste ballon duidelijk zichtbaar op het verloop van de ureter op beeldvorming. Vaak is er ook hydro-ureteronefrose aanwezig. Indien het foutief opblazen van de ballon heeft geleid tot een ureterruptuur, de meest gevreesde complicatie van het accidenteel plaatsen van een katheter in de ureter, wordt een urinoom gezien in de omgeving van de ruptuur, met extravasatie van contrast in dit gebied. Ook de aanwezigheid van vrije lucht doet schade aan de ureter vermoeden $[3,6,13]$.

Patiënten zonder schade aan de ureter kunnen conservatief behandeld worden. Dit omvat het leeg laten lopen van de katheterballon en het herpositioneren van de ballon in de blaas, zoals ook bij onze patiënte werd gedaan. Een ureterruptuur vereist een invasieve behandeling, middels plaatsing van een percutane nefrostomie of dubbel-J-stent. Indien de schade te uitgebreid is, is chirurgisch herstel noodzakelijk $[3,6,13]$.

Het in acht nemen van de basisprincipes van katheterisatie is de belangrijkste factor om foutieve plaatsing of migratie van een katheter te vermijden. Deze principes omvatten het bevestigen van urinedrainage uit de katheter alvorens de ballon op te blazen, controleren of de lengte van de katheter buiten het lichaam correct is, en het ledigen van de ballon en herpositioneren van de katheter bij plotse pijn. Een ander advies voor artsen en verpleegkundigen is het markeren van de lengte van de katheter die in situ is, en de corresponderende lengte aangeven op de nieuwe katheter, zodat de zorgverlener weet tot welke diepte de katheter opgevoerd kan en mag worden [3-5, 11-13]. Als preventieve maatregel wordt in de literatuur meermaals het wisselen over een voerdraad vermeld en dit is inderdaad een manier om een katheterwissel vlotter te laten verlopen, maar ook deze benadering zal plaatsing van een katheter in een ureter niet altijd kunnen vermijden [3, 5, 11, 12]. Om migratie van de katheter in het ostium te voorkomen, kan er bij risicopatiënten met een neurogene blaas een katheter met een korte tip gebruikt worden [3]. Ook het correct fixeren van de SPC op de buikwand of de TUC op het bovenbeen, verhindert migratie en is een aspect dat vaak vergeten wordt [10-12]. Routinematige beeldvorming middels echografie of cystoscopie om de ligging van de ballon na te gaan, is niet aangewezen. Dit zou te onpraktisch en patiëntonvriendelijk zijn, gezien de meeste katheterwissels in de thuissituatie plaatsvinden. Indien een zorgverlener toch twijfelt over de positie van de katheter, is het raadzaam om laagdrempelig een echografie uit te voeren en de ligging te bevestigen $[3,6,8,12]$.

\section{Conclusie}

Accidentele plaatsing van een katheter in de ureter is een zeldzame complicatie van zowel suprapubische als transurethrale katheterisatie. Gezien beide technieken zeer frequent worden uitgevoerd in de dagelijkse urologische praktijk, is het belangrijk deze diagnose in gedachten te houden bij elke patiënt met een katheter die zich presenteert met atypische en onbegrepen symptomen. De belangrijkste preventieve maatregel is het naleven van de basisprincipes van katheterzorg.

Open Access This article is distributed under the terms of the Creative Commons Attribution 4.0 International License (http:// creativecommons.org/licenses/by/4.0/), which permits unrestricted use, distribution, and reproduction in any medium, provided you give appropriate credit to the original author(s) and the source, provide a link to the Creative Commons license, and indicate if changes were made.

\section{Literatuur}

1. Harrison SC, Lawrence WT, Morley R, Pearce I, Taylor J. British Association of Urological Surgeons' suprapubic catheter practice guidelines. BJU Int. 2011;107(1):77-85.

2. English SF. Update on voiding dysfunction managed with suprapubic catheterization. Transl Androl Urol. 2017;6(Suppl 2):180-5.

3. Luo R, Lee SL, Ng FC, Koh LT. Inadvertent placement of a urinary catheter into the ureter: A report of 3 cases and review of the literature. Asian J Urol. 2017;4(4):256-61.

4. Kim MK, Kwangsung P. Unusual complication of urethral Catheterization: a case report. J Korean Med Sci. 2008;23(1):161-2.

5. Choi HJ, Lee CH, Shin H. Ureteral rupture caused by a Suprapubic catheter in a Male patient with spinal Cord injury: a case report. Ann Rehabil Med. 2016;40(6):1140-3.

6. Baker KS, Dane B, Edelstein Y, Malhotra A, Gould E. Ureteral rupture from aberrant Foley catheter placement: A case report. J Radiol Case Rep. 2013;7(1):33-40.

7. Dangle PP, Tycast J, Vasquez E, Geary B, Chehval M. Suprapubic cystostomy: a bizarre complication of catheter migration causing ureteric obstruction. Can Urol Assoc J. 2010;4(5):E127-8.

8. George J, Tharion G. Transient Hydroureteronephrosis caused by a Foley's catheter tip in the right ureter. Sci World J. 2005;5:367-9.

9. Borrero GO, Miller PR, Vora K, Nepjuk CA. Acute ureteral obstruction as a complication of suprapubic catheterization. Urol Radiol. 1987;9(3):171-3.

10. Shuaibin W, Haiqi M, Qin F, Haifeng Y. An unusual complication of Suprapubic catheter migration into the left ureter. Urol J. 2018;15(3):140-2.

11. Adeyemo B, Makovitch S, Foo D. A peculiar complication of suprapubic catheterization: recurrent ureteral obstruction and hydronephrosis. J Spinal Cord Med. 2013;36(2):166-9.

12. Vaidyanathan S, Soni B, Hughes P, Singh G, Oo T. Preventable long-term complications of suprapubic cystostomy after spinal cord injury: Root cause analysis in a representative case report. Patient Saf Surg. 2011;5(1):27.

13. Hale N, Baugh D, Womack M. Mid-ureteral rupture: a rare complication of urethral Catheterization. Urology. 2012;80(5):e65-e6. 
Nicolas Vos arts-assistent urologie

Eveline M.P. Broers uroloog

Elisabeth M. Groenewegen coassistent urologie, student geneeskunde

\section{Hier staat een advertentie.}

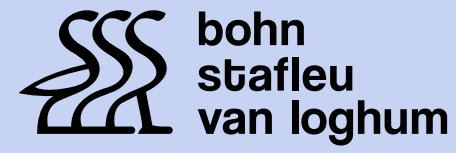

Springer Media

Houten 2019 